\title{
The Role of Pragmatics in Foreign Language Learning and Teaching
}

\begin{abstract}
:
Because learning English for communication is currently emphasized, the need for a re-consideration of the English learners' needs becomes necessary. Learners need to become more adept at producing and comprehending the pragmatic intent of an utterance, on the principle that less context implies more language. This paper aims at bringing into discussion the need and the importance of incorporating pragmatics into English language teaching in the English Department at University Constantine, 1. It focuses on the idea that efficient English language teaching must integrate pragmatic factors and issues in order to obtain satisfactory results not only in the classrooms but, more importantly, when learners use the English language in real and authentic contexts.
\end{abstract}

Key Words: Learners' needs, Pragmatics, Efficient English Language Teaching, Authentic Contexts.

\section{Meryem KEHAL}

Faculty of Letters and Languages Department of Foreign Languages

University of Mentouri

Constantine

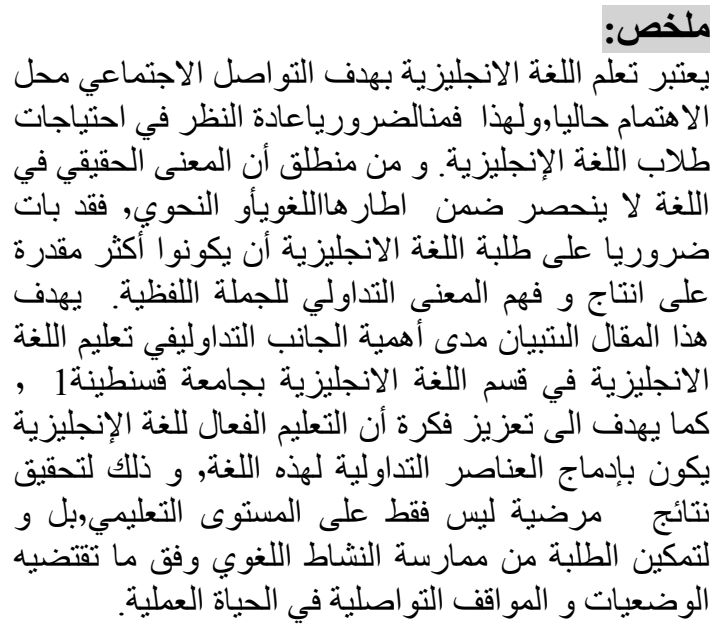

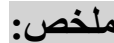

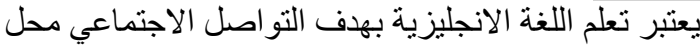

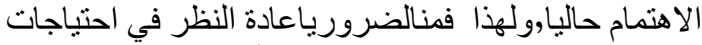

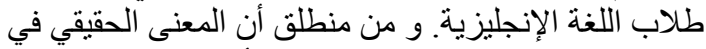

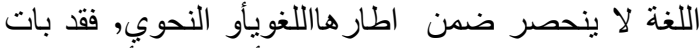
ضروريا على طلبة اللغة الانجليزية أن يكونوا أكثر مقدرة النقات

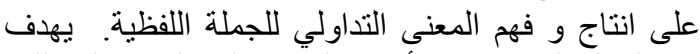

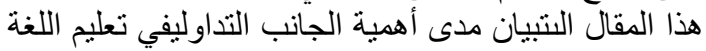

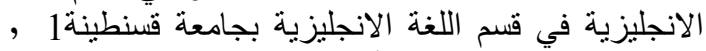

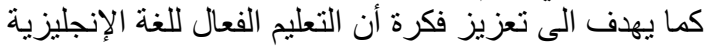

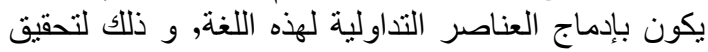

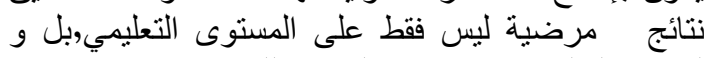
لتمكين الطلبة من ممارسة النشاط اللغوي وفق ماتئية ما تقتضيه الوضعيات و المو اقف التو اصلية في الحياة العملية.

\section{Introduction :}

Most Algerian leaners of English spend a significant amount of time pondering how exams are to be structured and contemplating which grammatical features are to be tested. As testing assessments typically evaluate the learner's linguistic competence through grammaroriented exercises, the learner may not feel it necessary to prepare for pragmatic-based activities. Teachers often overlook pragmatics in their teaching process due to different 
As such, the pragmatic component of language learning is often neglected. This may explain, to a great extent, the significant difference between native English speakers' performance and that of Algerian learners of English. It is right that the latter may know grammar and vocabulary, but most of them often fail to convey their intended messages and infer others' implied meanings. The fact that those learners are not sufficiently exposed to the English community and English speech behaviour makes it difficult for them to use the English language appropriately and efficiently. The lack of the cultural, social and pragmatic context in cross-cultural communication that learners might experience can lead to communication hindrances. On this account, it is important for language learners to be knowledgeable about fundamental cultural values and social norms of the target language.

The rise of English as an international language and the resultant status of English as a medium for global communication make it a necessary medium of communication much more than a medium of instruction only. Consequently, learning English as a foreign language should result in the use of this language as a means of communication rather than in conveying its theoretical knowledge.In fact, the goal of English foreign language leaning and instruction is no longer limited to general linguistic areas such as phonology, syntax and lexicon. It also includes the knowledge of the rules of language production and the patterns of interaction which vary from one speech community to another. In other words, it embraces the knowledge of English language pragmatics. Wolfson (1983) stated that without this specific knowledge, which considers the community-specific rules, foreign language learners will have difficulties at interpersonal communication when establishing conversations with native speakers.

Despite the plethora of research evidence that emphasizes the need for pragmatics instruction, English language instruction in Algeria still focuses mainly on grammar at the expense of pragmatic development of language learners. The common belief dominant in Algerian universities is that English language proficiency can only be gained by mastering English grammatical rules. However, Algerian learners show little success in coping with particular communication problems and in reflecting English language mastery. That is, in order to encode a given message in a given communicative process, most learners apply their pure linguistic knowledge but pay little attention to pragmatic knowledge and other pragmatic communicative skills and strategies.

This lack of pragmatic competence on the part of learners can lead to pragmatic failure and, more importantly, to a complete communication breakdown. This fact boils down to the realization that pragmatics is needed in the English learning process, since it has an influential role on communication success. Unlike traditional linguistics, pragmatics focuses on interactional and 
contextual factors of the target language. Considering this specific role of pragmatics makes it logical to know, first, what "pragmatics" means.

\section{2- The Essence of Pragmatics}

Pragmatics is a subfield of linguistics developed in the late 1970s and has been defined in various ways and from different perspectives. Crystal(1985), as one of the prominent and a pioneer in pragmatics, defined pragmatics as "the study of language from the point of view of users, especially of the choices they make, the constraints they encounter in using language in social interaction and the effects their use of language has on other participants in the act of communication."'(240)

Following this definition, it is possible to notice that only pragmatics takes the user of the language into account in analysing the intended meaning. One of the core principles of pragmatics is that there is no language without users, and that the same utterance may mean different things if said by distinct people in different situations. Pragmatics claims that there is an association between grammar and context. That is to say, in order to convey the desired meaning, the language user has to choose different structures according to the context he/she is in. Elsewhere Crystal (1987) noted that pragmatics includes those "factors that govern our choice of language in social interaction and the effects of our choice on others."(120) Pragmatics, therefore, can be seen as the study of the relationship between language context and users and the resulting grammatical forms.

In the words of Kasper (1989), pragmatics "is the study of acting by means of language, of doing things with words."(39) In accordance with this view, pragmatics is defined as the study of "meaning in interaction" (Thomas, 1995: 22).In Rose and Kasper's view (2001), pragmatics is the study of communication in its sociocultural context. Yule (1996), however, proposed another definition of pragmatics and described it as "the study of the relationship between linguistic forms and the users of those forms."(4) $\mathrm{He}$ mentioned that pragmatics examines the intentional human action and the linguistic choices speakers make in accordance with who they are talking to, when, where, and under what circumstances. Pragmatics, then, is the study which analyses language use in context. It is more about the communicative intent or the speaker meaning rather than the utterance meaning.

As shown above, all definitions have been proposed in different manners and various ways, but still hold the same specific essence of pragmatics, namely the study of language use and its appropriateness. For English native speakers, this appropriateness is regarded as something more natural than it is for foreign language learners who have to practice it and reflect on their language choices.

3- Pragmatic Competence

Although researchers did not use the term "pragmatic competence" explicitly, they did recognize the efficiency of pragmatic competence as an 
essential part of communicative competence and also the significance of language use in context. The term pragmatic competence was first explicitly mentioned by Bachman in 1990. He divided language competence into two discrete components; organizational competence and pragmatic competence.

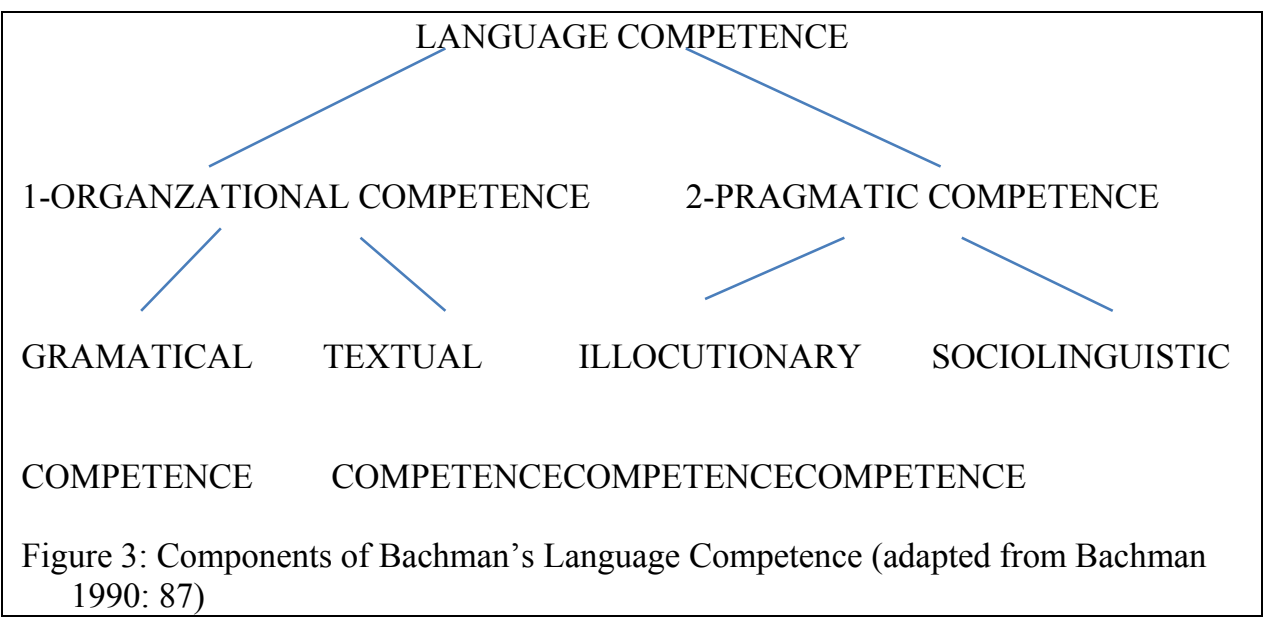

According to Bachman (1990), organizational competence refers to "the knowledge of linguistic units and the rules of joining them together." (87) It is broken down into two types of abilities: Grammatical competence which refers to the knowledge of vocabulary, morphology, phonology and syntax, and textual competence which consists of the knowledge required to join utterances together to form a unified whole.

Bachman's pragmatic competence consists of illocutionary competence (the knowledge of speech acts and language functions) and sociolinguistic competence (the ability to use language appropriately in different sociocultural contexts.) That is to say, pragmatic competence in Bachman's model refers to the ability to use language for different purposes and functions and to comprehend illocutionary force in different contexts of communication.

Similar to Bachman's definition, Celce-Murcia and Olshtain (2000) described pragmatic competence as "a set of internalized rules of how to use language in socioculturally appropriate ways, taking into account the participants in a communicative interaction and features of the context within which the interaction takes place." (20)

Seen from this perspective, pragmatic competence requires the knowledge of linguistic rules and the ability to use those rules appropriately. This is, in fact, what has been already proposed in Bialystok's definition of pragmatic competence:

Pragmatic competence entails a variety of abilities concerned with 
the use and interpretation of language in contexts. It includes speakers' speakers' ability to use language for different purposes - to request, to instruct, to effect change. It includes listeners' ability to get past the language and understand the speaker's real intentions, especially when these intentions are not directly conveyed in the forms - indirect requests, irony and sarcasm are some examples. It includes commands of the rules by which utterances are strung together to create discourse (1993: 43).

All in all, "pragmatic competence" can be defined as the ability which involves knowledge beyond the level of grammar and that helps achieve successful communication. It can be recognized as one of the critical components that help language learners become communicatively competent. Accordingly, it can be proposed that without pragmatic competence, it is difficult to participate in ordinary social life.

\section{3- The Role of Pragmatics in Foreign Language Classrooms}

. Compared to real-life interactions outside the classroom interactions, it has been clearly noticed that traditional structure-based foreign language classrooms have been considered poor input environments for developing pragmatic ability in the target language. Foreign language instruction in such classrooms focuses mainly on grammar and ignores the pragmatic development of language learners. This fact results in significant differences between foreign language learners and native speakers in the area of language use. In response to the failure of 'form' approaches in developing learners' communicative ability in real-life situations, the need for change became a must. In many second and foreign language teaching contexts, curricular materials developed in recent years either include strong pragmatic components or even adopt a pragmatic approach as their new and effective orientation to teaching.

Studies have found that when pragmatics is not offered, opportunities for developing pragmatic competence are quite limited (Kasper, 2000). Regarding this particular point, Kasper has clearly mentioned that

In a foreign language situation [...], students lack the need and opportunity of genuine communication in the target language; therefore, it is nearly impossible for students to develop pragmatic ability [...] the ability to interpret utterances in context, especially when what a speaker says is not the same as what the speaker means; to carry out communicative action effectively and interact successfully in different environments and with different participants (2000:1).

In this case, it is arguable that without pragmatic instruction, differences in pragmatics are likely to show up in the English of learners regardless of their linguistic proficiency. As it has been previously discussed, language 
proficiency is not solely based on grammatical competence. Thus, the proficient language learner in grammar cannot be assumed to be equally proficient in the appropriate pragmatic usage of the language. English learners and especially foreign ones may not have the opportunity to observe some, if not all, targeted pragmatic features without being effectively involved in learning such kind of target language aspects. Consequently, it is assumed that foreign language learners cannot be expected to develop their pragmatic competence on their own without a focus on pragmatic instruction (Kasper, 2000). This, in turn, makes the role of pragmatics even more important and necessary in foreign language classrooms.

Needless to say, Algerian classrooms of English have difficulties in providing authentic pragmatic input of the English language. This fact impedes learners' pragmatic development in the classrooms. Actually, Algerian classrooms for English provide little or no opportunity for learners to interact with native speakers or to experience real-life situations, compared with second language learners in second language environment. Even teachers find it difficult to maximize a full range of human interactions in such traditional English FL classrooms. Regarding this point, Cook (2001) stated that in foreign-language classrooms, the target language tends to be viewed as an object of study instead of a means of socialization and communication. It is, indeed, the case in many Algerian classrooms where English is regarded as an object of study and not as a medium of interaction.

The ability to communicate effectively in many different situations and contexts involves the ability to control a wide range of language functions such as requesting, refusing, promising and apologizing. Unfortunately, most FL learners face difficulties in dealing with such language functions. They often lack the knowledge of what counts as cooperative and polite. The act of refusing, for example, is one of the most challenging communicative acts for foreign language learners since "the inability to say 'no' clearly and politely $[\ldots]$ has led many non-native speakers to offend their interlocutors."(Beebe and Takahashi, 1987:133)

Algerian teachers have become familiar with some expressions that are generally used by their students like "What?!", instead of "I beg your pardon!", or even "pardon!"; "repeat!" instead of "would you repeat, please!" or " please, repeat!"

Committing such kind of pragmatic deviations may easily result in various consequences which are often interpreted at a social level rather than an outcome of the language learning process. Instead of being considered an uneducated person, the foreign language user, then, may appear uncaring, abrupt or brusque in social interactions. Yet, in all cases, a good communication may effortlessly be hindered. As a case in point, most of Algerian learners of English do not know the various degrees of politeness that 
are proper to the communicative interaction in which they are involved. In other words, they cannot adjust the level of directness and indirectness in the different communicative interactions they may go through.

Knowing such kind of pragmatic strategies in dealing with different communicative situations, like directness or indirectness, can really intensify or soften communicative acts. Using pragmatic strategies in social interactions is a facilitative tool that compensates for deficiencies in communication. Their function, therefore, is to promote and empower communication. For this additional reason, pragmatic knowledge is of great help to FL learners as it deals with the effectiveness and social cohesiveness of communicative actions. This particular competence, also, includes the knowledge of the effective pragmatic strategies that enable learners to communicate successfully. These reasons, indeed, impose huge demands on pragmatics involvement in language teaching and learning.

At this level of discussion, it can be said that the relationship between pragmatics and language learning and teaching is clear and should be emphasized. In accordance with this view, Bouton stated that

Pragmatics and language learning are inherently bound together. Pragmatics provides language teachers and learners with a research based understanding of the language forms and functions that are appropriate to the many contexts in which a language is used-an understanding that is crucial to a proficient speaker's communicative competence (cited in Guerra, 2003: 10).

Accordingly, pragmatics-based teaching is a must and developing pragmatic competence of a language is a necessity.

In developing a pragmatically-oriented approach, learners would have more opportunities to interpret language input. This specific approach aims at developing a gradual awareness of the mismatch between the foreign-languagelearner communicative performance and that of proficient users of the language. The implementation of this approach, in fact, imposes a complete reorientation of the foreign language curriculum. It is completely different from structure-based approaches to language teaching in that it relies on the enhancement of the learners' communicative skills and focuses on the pragmatic aspect of communication. One of the core principles of this teaching approach is to develop learner' language awareness of how the target language is typically used in communication. It focuses on the efficient engagement in communicative activities to gain familiarity and control over the appropriate pragmatic forms and strategies for different social circumstances. Such activities may facilitate access to data representing authentic discourse and 
meaningful interaction in the target language. This, in turn, helps in fostering the analytical thinking skills of learners. Such activities may facilitate access to data representing authentic discourse and meaningful interaction in the target language. This, in turn, helps in fostering the analytical thinking skills of learners.

\section{4- A pragmatic-based Activity}

The activities that are pragmatically-based should be designed in a way that focuses on the pragmatic rules for language use and more importantly on how to implement those rules in real-life situations.

Learners are in need to transform the learned knowledge into competence. Therefore, adequate opportunities to put the learned knowledge into use is of prime importance (Kasper, 1997). As previously mentioned, FL learners cannot be expected to develop their pragmatic competence on their own. This puts the pressure on the teachers who should plan lessons and draw learners' attention to pragmatic elements through practice. For foreign language teaching to be efficient, it has to be practiced. This performance requires a real experience and an efficient application of linguistic knowledge through particular activities that address the learning of the targeted pragmatic aspects of language.

The following activities, adapted from Brock and Nagasaka (2005), were designed to rehearse the pragmatic knowledge of learners as a way to develop their pragmatic strategies for communicating successfully.

The first activity has been developed by using a politeness continuum. The first step the teacher has to do is to know the different ways students may make their requests of both their classmates and teacher. The teacher may, then, propose the politeness continuum as follows:

Indirect: I forgot my pencil. /My pencil's broken.

Direct: Lend me a pencil.

Polite: Could I borrow a pencil, please? /Would you mind lending me a pencil?

Familiar: It'd be terrific if I could borrow your pencil.

After the teacher has explained and illustrated the politeness continuum, studentsmake requests of each other using an activity sheet similar to this:

1. Polite: Ask a classmate to lend you his/her ruler. Measure this paper and writethe width along with the classmate's name here.

2. Familiar: Ask a classmate to lend you 10 dollars. Write his/her name here.

3. Indirect: Ask a classmate to lend you his or her pencil. Write his or her namehere

4. Polite: Ask a classmate to sign his/her name. (21)

During final discussion, the teacher has to make sure that the students have really captured the objective of this activity, and understood the pragmatic necessity in making requests. 
The second activity was proposed to reinforce students' knowledge of how pragmatics and communicative situations are intrinsically related. In this activity, the students are exposed to a continuum of choices where they can notice the different openings and distinct requesting strategies.

Example Openings:

Indirect: It's time to get started.

Direct: Sit down now.

Polite: Would you sit down, please?

Familiar: Boys and girls, it would be helpful if you could take a seat.

Example Requests:

Indirect: It's cold in here. /I'm freezing.

Direct: Close/Shut the window.

Polite: Could you close the window, please? / Would you mind closing the window?

Familiar: Be a dear and close the window. /Would you close the window for us? (23)

Such activity may intensify the students' pragmatic awareness in using the language. It may also strengthen the idea of how language and pragmatic strategies are highly affected by the relationship interlocutors have with each other while communicating.

\section{Conclusion}

What should be emphasized, at the end, is that there is no best way for teaching pragmatics. What matters, however, is that students have to learn the difference in not only language per se, but also sociocultural norms and values underlying language use. This fact places a profound emphasis on the necessity of imparting knowledge about and raising awareness of pragmatic aspects and strategies which are of great help in developing the overall language competence. What foreign language learners are in need of, then, is to process language pragmatically to achieve more competency in their language learning. This serious need, in turn, emphasizes the idea that foreign language instruction should be purposefully built on pragmatic knowledge and pragmatic understanding of language.

\section{References}

Bachman, L.F. 1990. Fundamental Considerations in Language Testing.

Oxford: Oxford University Press.

Beeb, L.M., and Takahashi,T.1987.The Development of Pragmatic

Competence by Japanese

Learners of English. JALT Journal, 8(2), 131-155.

Bialystock,E. 1993.Symbolic Representation and AttentionalControl in Pragmatic Competence. In 
Kasper, G. and Blum-Kulka (eds.), Pragmatic Interlanguage (PP.4357). Oxford University

Press.

Brock, M.N. and Nagasaka, Y. 2005. Retrieved May 16,2014, from http://ojs.lib.byu.edu/spc/index.php/ TESL/article/view/3808/3554

Celce-Murcia, M. and Olshtain, E.2000. Discourse and Context in Language Teaching: A Guide for

Language Teachers. Cambridge: Cambridge University Press.

Cook, H.2001. Why can't Learners of Japanese as a Foreign Language

Distinguish Polite from

ImpolieSpeech Acts Styles? In Rose, K. R., and Kasper, G. (eds.), Pragmatics

in Language

Teaching (pp.80-102).New York: Cambridge University Press.

Crystal, D. 1985. A Dictionary of Linguistics and Phonetics ( ${ }^{\text {nd }}$ ed.). Oxford:

Blackwell.

Crystal, D. 1987. The Cambridge Encyclopedia of Language. Cambridge:

Cambridge University

Press.

Guerra, A.B. F. et al. 2003. Pragmatic Competence and Foreign Language

Teaching : An Introduction.

UniversitatJaum 1.

Kasper, G. 1989. Interactive Procedures in InterlanguageDiscourse. In W.

Oleksy (ed.), Contrastive

Pragmatics (pp.189-229). Amsterdam: John Benjamins.

Kasper, G. 1997. Can Pragmatic Competence be taught? Retrieved June, 27, 2013, from

http://www.nflrc.hwaii.edu/networks/NW06/default.html

Kasper, G. 2000. Pragmatics in EFL Contexts. Retrieved July 06, 2013, from

http:// www/jalt

publications. org/ tlt/articles/2000/07/Kasper.

Rose, K. R. and Kasper, K. (eds.). 2001. Pragmatics in Language Teaching.

Cambridge: Cambridge

University Press.

Thomas, J.1995. Meaning in Interaction: An Introduction to Pragmatics.

London: Longman.

Wolfson, N.1983. An Empirically Based Analysis of Complementing in

America English. In N.

Wolfson and E. Judd (eds.), Sociolinguistics and Language Acquisition (pp.8295).

Rowley, MA: Newbury House Publishers.

Yule, G. 1996. Pragmatics. Oxford: Oxford University Press. 